\title{
La Lucha contra la evasión y fraude fiscal internacional como fuente de financiación del Desarrollo Sostenible
}

The Fight against evasion and international tax fraud as a source of financing for Sustainable Development

Jorge Marcelino Junior

Doctor en Derecho y Ciencias Políticas por la Universidad de Barcelona.

Investigador invitado en el Centre d'études sur la fiscalité des entrepises, París; IFA, (Rotterdam) y IBFD.

Abogado especialista en Planificación Patrimonial, Estructuras de Centros Offshore

e Inversión Extranjera Directa

E-mail: jorge@marcelino.adv.br 


\section{Resumen:}

La importancia de la lucha contra la evasión y el fraude fiscal es esencial con el fin de lograr el cumplimiento de los Objetivos de Desarrollo Sostenible, que también han venido a ser recogidos en la Agenda 2030.

Con este fin, en primer lugar, se expone la trascendencia y ubicación de la fiscalidad dentro de los ODS. A continuación, se analiza, sobretodo desde el punto de vista doctrinal, la actual problemática conceptual de la evasión y la elusión fiscal, de cuándo nos encontramos ante una situación lícito o ilícita en el momento que se trata de evadir o eludir una obligación tributaria. Finalmente, se exponen pormenorizadamente las principales medidas internas de lucha contra la evasión fiscal.

A partir de todo lo anterior, en el presente artículo se concluye sobre la importancia de la recaudación tributaria y el establecimiento de políticas fiscales para conseguir los Objetivos de Desarrollo Sostenible a escala mundial. En este sentido, se pone en relieve la importancia de establecer una cooperación entre los países desarrollados y menos desarrollados con el fin de conseguir combatir la evasión fiscal a nivel internacional generando más financiación pública para todos los países, particularmente a los más pobres que son los más afectados. En consecuencia, habría menos desigualdad social y una mejor redistribución de las riquezas. De allí, la importancia de la reforma de los sistemas tributarios y la armonización de las políticas fiscales que permitan paliar la evasión y la planificación fiscal agresiva.

Palabras clave: políticas fiscales, fraude y evasión fiscal internacional, fiscalidad, Objetivo de Desarrollo Sostenible (ODS), Agenda 2030, medidas contra la evasión fiscal, armonización, cooperación, redistribución de las riquezas, reducción desigualdades sociales.

Abstract: The importance of the fight against tax evasion and fraud is essential to achieve compliance with the Sustainable Development Goals, which have also been included in the 2030 Agenda.

To this end, firstly, the importance and location of taxation within the SDGs is exposed. Next, an analysis is made, especially from a doctrinal point of view, of the current conceptual problem of tax evasion and avoidance, of when we are faced with a legal or illicit situation when it is a question of evading or evading a tax obligation. Finally, the main internal measures to combat tax evasion are explained in detail. 
Based on all of the above, this article concludes on the importance of tax collection and the establishment of fiscal policies to achieve the Sustainable Development Goals worldwide. In this sense, the importance of establishing cooperation between developed and less developed countries is emphasized to combat tax evasion at the international level, generating more public funding for all countries, particularly the poorest, which are the most affected. Consequently, there would be less social inequality and a better redistribution of wealth.

Regarding when the avoidance of the fulfilment of a tax obligation should be considered a lawful or illicit nature, the importance of determining the said line of separation in the legal field is manifested in practical reality. Hence, the importance of the reform of tax systems and the harmonization of tax policies to mitigate evasion and aggressive tax planning.

Key Words: tax policies, fraud and international tax evasion, taxation, Sustainable Development Goal (SDG), 2030 Agenda, measures against tax evasion, harmonization, cooperation, redistribution of wealth, reduction of social inequalities. 


\section{i. Los Objetivos de Desarrollo Sostenible y la armonización de políticas fiscales}

En 2002, la formación de la Campaña de Desarrollo del Milenio de las Naciones Unidas fue responsable de la creación de 8 (ocho) Objetivos de Desarrollo del Milenio $(\mathrm{ODM})^{1}$ que serian buscados para el año 2015. Con estos objetivos, la ONU tenía la intención de promover el desarrollo mundial mediante la erradicación de la pobreza y el hambre, así como mediante la promoción de la educación, la salud y la igualdad de género para todos. En aquel momento, la sostenibilidad ambiental era solo uno de esos objetivos, diferente del énfasis dado al tema en las siguientes Asambleas.

En 2013, la Asamblea General de la ONU ha promocionado un evento para monitorear los esfuerzos y resultados hacia los ODM. El documento producido después de la Asamblea ${ }^{2}$ propuso una nueva reunión en 2015 a favor de la creación de nuevos objetivos. La propuesta utiliza los ODM como apoyo para los 17 (diecisiete) Objetivos de Desarrollo Sostenible (ODS), agregando nuevos propósitos a los desafíos actuales del avance económico, social y ecológico.

Esto se ha hecho desde 2015, los ODS han sido parte de la Agenda 2030, que reúne las acciones adoptadas por la Cumbre de la ONU para avanzar en el desarrollo humano de manera sostenible. En general, se centran en reducir la desigualdad mediante la erradicación de la pobreza y el hambre, la salud, la educación de calidad, la igualdad de género; Crecimiento económico con innovación en infraestructura y consumo y producción responsables.

Uno de los aspectos clave para el desarrollo de los ODS y el logro de los objetivos de la Agenda 2030 es la fiscalidad; A pesar de no constituir un ODS específico, la importancia de la recaudación tributaria y de las políticas fiscales se mencionan varias veces en los sub-objetivos dado su papel en la financiación de las actividades Estatales, así como su carácter redistributivo de los ingresos, que también constituye una herramienta para reducir las desigualdades.

En el décimo objetivo, que establece la reducción de la desigualdad dentro y entre países $^{3}$, la fiscalidad se hico constar en dos sub-objetivos: sub-objetivo 4: adopción de políticas fiscales como un medio para lograr progresivamente la igualdad; y sub-objetivo 5: mejorar la inspección y regulación de estas medidas.

En el objetivo 17, que prevé el fortalecimiento de los medios para implementar y revitalizar la asociación mundial para el desarrollo sostenible", la tributación puede estar relacionada con los sub-objetivos 1, 2 y 5 relacionados con la inversión extranjera en los países menos desarrollados.

La situación señalada por la ONU muestra que, para reducir el contraste social, es necesario combatir la desigualdad no solo dentro de las naciones, sino principalmente entre

\footnotetext{
${ }^{1}$ Proyecto del Milenio - encargado por el Secretario General de las Naciones Unidas. 2002

${ }^{2}$ Naciones Unidas - Asamblea General. Documento final del acto especial de seguimiento de la labor realizada para lograr los Objetivos de Desarrollo del Milenio. 2013 ${ }^{3}$ Objetivos de Desarrollo Sostenible: 10.4 Adoptar políticas, especialmente protección fiscal, salarial y social, y lograr
progresivamente una mayor igualdad.
} 
ellas. La cooperación internacional para que haya armonía entre los sistemas tributarios es fundamental para este esfuerzo, ya que evita la evasión y los delitos de fraude fiscal ${ }^{4}$.

En 2015, también se celebró la Tercera Conferencia Internacional sobre Financiación para el Desarrollo, en la cual la Asamblea General de la ONU adoptó la Agenda de Addis Abeba ${ }^{5}$. Esta agenda propone que la estandarización de las políticas para que el comercio internacional sea una herramienta para el crecimiento social y económico, y no sea perjudicial para las naciones en desarrollo que tienden a tener lagunas en la legislación fiscal.

Por lo tanto, de conformidad con la Agenda, los países desarrollados deberían ayudar a los países en desarrollo a mejorar sus sistemas tributarios, considerando que una de las razones fundamentales de la necesidad de recaudar impuestos está relacionada con la redistribución de la riqueza. Gravar los mayores activos y redistribuir a la población a través de políticas económicas y sociales como educación, salud y seguridad pública ${ }^{6}$.

En una reunión de la Cumbre de la ONU con las principales organizaciones económicas y financieras internacionales, el secretario general, António Guterres, hizo la siguiente solicitud ${ }^{7}$ :

"Pido a la comunidad internacional que establezca mecanismos efectivos para combatir la evasión fiscal, el lavado de dinero y los flujos financieros ilícitos, para que los países en desarrollo puedan movilizar mejor sus propios recursos. La imposición eficiente es esencial para promover un crecimiento más inclusivo y sostenible. Es esencial que la globalización funcione para todos ".

El objetivo de la reforma de las leyes fiscales en los países en desarrollo es cerrar las lagunas que hacen que estas naciones sean refugios fiscales, interfiriendo con los movimientos financieros y de mercado, y reduciendo una posible recaudación de impuestos de otro estado. En otras palabras, la ONU aboga por la cooperación entre los países desarrollados y en desarrollo para lograr una mejor armonización entre las políticas fiscales adoptadas por sus países miembros, lo que haría que la recaudación fuera más efectiva y financiara la asistencia de los Estados y las políticas redistributivas ${ }^{8}$.

Las interpretaciones agresivas con respecto a las leyes fiscales son comunes en las multinacionales y las personas ricas y son extremadamente perjudiciales para los

\footnotetext{
${ }^{4}$ HILLING, Axel; OSTAS, Daniel. Corporate Income Taxation, CSR and the UN's 2030 Agenda for Sustainable Development. 2018

5 UN Tercera Conferencia Internacional sobre la Financiación para el Desarrollo. Documento final de la Tercera Conferencia Internacional sobre la Financiación para el Desarrollo: Agenda de Acción de Addis Abeba. 2015

6 “We can't meet the Sustainable Development Goals (SDGs) without taxation. To bridge the SDG financing gap, developing countries will need to tax more and better. The donor community has already stepped up its efforts to support them, committing to double its collective provision of technical assistance on taxation between 2015 and 2020." Hearson, Martin. Fair tax for development. UNA-UK, 2019.
}

\footnotetext{
${ }^{7}$ Reportaje Naciones Unidas Brasil: La ONU llama a los países en desarrollo a luchar contra la evasión fiscal por objetivos globales. 19/02/2019.

${ }^{8}$ BUFFON, Marciano. Tributação e dignidade humana: entre os direitos e deveres fundamentais. Porto Alegre: Livraria do Advogado Editora, 2009. p. 100.
} 
países desarrollados, que a menudo pierden ingresos considerables debido a fallas en las leyes fiscales de los países en desarrollo, lo que genera un déficit fiscal en ambos países.

Una investigación realizada en 2019 por la red internacional independiente Tax Justice Network fue señalado en un informe de la ONU: Reino Unido. Seis países en desarrollo se verán privados de 2018 a 2030 de aproximadamente 540 millones de euros por evasión y fraude fiscal por parte de "British American Tobacco Plc", la compañía tabacalera más grande del mundo.

Los países desarrollados suprimen todas las aperturas en la legislación fiscal, además de recibir impuestos sobre las materias primas recolectadas en los países en desarrollo, apoyando la necesidad de una revisión de los tratados internacionales. Por otro lado, los países en desarrollo no tienen las herramientas necesarias para abordar los problemas fiscales, en comparación con los países desarrollados, por lo que terminan perdiendo ingresos. La relación es compleja, ya que en la mayoría de los casos estos países, desarrollados y en desarrollo, no comparten los mismos intereses.

La inclusión de un sistema eficiente de recaudación de impuestos en los países en desarrollo tiene, en el lado positivo, la generación de apoyo social del gobierno, que trabaja a favor de los ODS, erradicando el hambre y la pobreza e invirtiendo en educación de calidad, salud y seguridad pública ${ }^{9}$.

Con respecto al uso correcto de los impuestos en los países en desarrollo, el economista Nicholas Kaldor escribió en el artículo: “¿aprenderán a gravar los países subdesarrollados?":

"Cualquiera sea la ideología o política predominante de un gobierno en particular, debe expandir constantemente una gama de [...] servicios [...] como prerrequisito para el desarrollo del país. Estos servicios deben financiarse con los ingresos del gobierno. Además de satisfacer estas necesidades, los impuestos [...] proporcionan las herramientas más apropiadas para aumentar la economía para la formación de capital de fuentes nacionales." 10

La observación de Kaldor provino de la baja recaudación de impuestos del gobierno, algo que es común en estos países, defendido como un elemento clave para entender por qué están subdesarrollados.

La legislación fiscal que se construye teniendo en cuenta las normas internacionales está diseñada para apoyar el desarrollo económico sostenible que debe reducir la desigualdad dentro de la nación que lo aplica, y también entre naciones, al reducir la evasión fiscal y el fraude ${ }^{11}$.

\footnotetext{
${ }^{9}$ LONG, Cathal; MILLER, Mark. Taxation and the Sustainable Development Goals: do good things come to those who tax more? 2017

${ }^{10}$ KALDOR, Nicholas. Will Underdeveloped Countries Learn To Tax? 1963.

${ }^{11}$ AIREY, Siobhan. Taxation Untapped: the potential of the UN Sustainable Development Goals to promote progressive International Tax Reform. 2020
} 
Las medidas, previstas en las reformas legislativas, deben aplicarse progresivamente para que no afecten las operaciones económicas existentes en el país. Los impuestos excesivos pueden tener efectos negativos, evitando las inversiones privadas, pero si las políticas se diseñan adecuadamente, transforman la recaudación en recursos en servicios a la población, lo que brinda estabilidad al sistema.

Dando la oportunidad de adaptarse y trabajar junto con varias políticas nacionales individuales e internacionales, la iniciativa de la ONU para enfatizar la importancia del sistema tributario para la reducción de la desigualdad, a través de los ODS, tiene la competencia para promover una reforma gradual en el sistema tributario internacional .

[...] El objetivo 17 de los ODS podría usarse como trampolín para este debate [...] combatir la evasión fiscal de las multinacionales liberaría niveles significativos de financiación pública para todos los países, pero generaría comparativamente más fondos para Los países más pobres, ya que actualmente están más afectados por la evasión fiscal que los países más ricos, [...] requieren una estrategia para defender la domesticación y la politización de la agenda política internacional para la reforma fiscal y una rearticulación de los impuestos como instrumento de la gobernanza será operada por un estado orientado al público en interés público [...] Si estos elementos son parte de una estrategia del objetivo 17.1 de los ODS 17, tal vez se cumpla su promesa de "no dejar a nadie atrás"."

En resumen, si la tributación es un aspecto esencial para el Desarrollo Sostenible, la reforma de los sistemas tributarios es la herramienta necesaria para lograr los niveles de eficiencia y armonización necesarios para mitigar el fraude y la evasión fiscal, ya que serán eliminados Oportunidades para una planificación fiscal agresiva.

\section{ii. Medidas internas de combate a la evasión fiscal}

En términos concretos, hablar en armonización de políticas fiscales es hablar de adopción de políticas semejantes por los Estados. Dichas políticas que de una banda expurgan disfunciones y huecos legislativos, aumentando la presión fiscal sobre los contribuyentes, pero de otra banda reconocen políticas fiscales de otros países permitiendo la manutención de las relaciones comerciales.

Esto se hace, conforme expuesto, a través de medidas internas (fuentes internas) e internacionales (fuentes internacionales), muchas ya existentes y fuertemente incentivadas por Organismos internacionales como la OCDE. Veamos algunas de dichas políticas:

\section{Cláusula General Antielusiva}

La necesidad de refutar actos o negocios jurídicos practicados por contribuyentes pautados en simulaciones y estructuras meramente aparentes ${ }^{12}$ (y que resultaban en

\footnotetext{
${ }^{12}$ Conforme el ejemplo previsto por João Francisco Bianco: "No exemplo em que homem casado vende bem imóvel a sua amante por preço vil, a transferência da propriedade do bem imóvel será submetida ao regime de tributação aplicável à hipótese de doação (ato dissimulado) e não de compra e venda (ato simulado). Esse critério, adotado pela jurisprudência de nossos Tribunais, está agora positivado no ordenamento. Isso por que o parágrafo único do artigo 116 do CTN, introduzido pela Lei Complementar $n^{\circ}$ 104, de 10 de janeiro de 2001, acabou por reconhecer que os negócios simulados
} 
perjuicios considerables al erario) hizo con que los Estados, fundamentalmente a través de la jurisprudencia, iniciasen una recepción gradual de conceptos y modelos jurídicos aplicados en otras ramas del derecho, relativizando primados fiscales como el principio de la estricta legalidad, en la búsqueda por la eficiencia de la recaudación de impuestos, de forma a tributar tales operaciones basadas en la substancia y no en la forma.

La formación de la llamada "interpretación económica" marca el comienzo de la decadencia del Estado Liberal en los años 70, cuando institutos como la autonomía de la voluntad, el carácter absoluto de la propiedad, la completa autonomía del derecho tributario pasaron a ser analizados a través del prisma de la supremacía del interés público ${ }^{13}$.

Es en este escenario que vemos el nacimiento de algunos institutos que intentan clasificar, o establecer patrones para las conductas adoptadas por contribuyentes frente a la necesidad de cumplimiento de obligaciones tributarias que serían ordinariamente verificadas.

Entre ellos vemos inicialmente la formación de los conceptos de evasión y elusión, no obstante han sufrido mutaciones y originariamente buscaban llenar el binario lícito o ilícito. De esta manera, la primera clasificación de las conductas adoptadas frente a la capacidad recaudatoria de los Estados tiene como criterio fundamental, único y exclusivamente, la ilicitud ${ }^{14}$.

devem ser submetidos ao regime de tributação aplicável aos negócios que se pretendeu dissimular.” BIANCO, João Francisco. Transparência Fiscal Internacional. São Paulo: Dialética, 2007. p. 110.

\footnotetext{
${ }^{13}$ Se debe destacar el abandono de la escuela conceptualista, que subyugaba la necesidad de evaluación empírica de los hechos generadores, analizándolos sobre la dimensión legalista y desconsiderando aquellos que no guardaban identidad perfecta con la hipótesis de imposición descrita por el legislador, no obstante haya tenido su ápice en el final del siglo pasado, presenta orígenes mucho más antiguas, pero una vez en la jurisprudencia alemana, que ya en el art. 4o del Código Tributario Alemán de 1919, predecía la llamada consideración económica del hecho generador (wirtschaftliche Betrachtungsweise). Para profundizar véase: KRUSE, Heinrich Wilhelm. Steuerrecht. C. H. Beck. München, 1969; GIANINI, Achile Donato. Istituzioni di Diritto Tributario. Milano: Ed. Giuffrè, 1948.; CANTO, Gilberto de Ulhoa. Legislação Tributária, sua Vigência, sua Eficácia, sua Aplicação, Interpretação e Integração. Revista Forense 267: 25-30, 1979.; DÓRIA, Antônio Roberto Sampaio. Elisão e Evasão Fiscal. São Paulo: Bushatsky, 1977; BEKER, Enno. ZurAuslegung der Steuergesetze. Steuerund Wirtschaft. Berlim, 1924; GRIZIOTTI, Benvenuto. Principios de Política, Derecho y Ciencia de la Hacienda. Buenos Aires: Ed. Depalma, 1935; FALCÃO, Amilcar Araujo. Hermenêutica no Direito Tributário. In: MORAES, Bernardo Ribeiro. Interpretação no Direito Tributário. São Paulo: Saraiva, 1975.

14 "Sendo o critério da ilicitude aquele decisivo para distinguir entre evasão e elisão de tributos, passou-se em revista crítica sobre diversos preconceitos da doutrina tradicional acerca do conceito de ilícito civil. Verificou-se basicamente que ilícito civil é um ato jurídico contrário ao direito e imputável a um sujeito. Separou-se da essência do conceito de ilícito civil os tradicionais elementos de culpa, dano e indenização. Em especial, verificou-se a ilicitude dos atos nulos, como a fraude à lei ou a simulação. Feito isso, constatou-se que, hodiernamente, a ilicitude já não se limita a condutas contrarias a regras, como a simulação ou fraude (ilicitude típica), mas estende-se a condutas contrárias à princípios (ilicitude atípica)." YAMASHITA, Douglas. Elisão e Evasão de Tributos. Planejamento Tributário:Limites à Luz do Abuso do Direito e da Fraude à Lei. p. 64;. Converge a la exposición de Novoa: “Así pues, podemos decir que la elusión limita, por una parte con la evasión o el ilícito. Dejamos de jugar en el campo de la elusión cuando entramos en el terreno de juego del ilícito fiscal." p. 36.
}

Acuérdese que se está delante de un ilícito fiscal, no habiendo necesidad del acto practicado por el contribuyente ser un ilícito penal: “(...) consistem em atos ilícitos fiscais, mas não necessariamente criminais. ”CAVALI, Marcelo Costenaro. Cláusulas Gerais Anti elusivas: reflexões acerca de sua conformidade constitucional em Portugal e no Brasil. p. 27. 
Así, definimos los conceptos:

- Evasión: se caracteriza por la práctica de un acto ilícito, que visa la eliminación o reducción de carga tributaria, aunque emplea medios ilícitos para alcanzar el deseado fin evasivo ${ }^{15}$;

- Elusión: se caracteriza por la práctica de un acto lícito, que también visa eliminar o reducir carga tributaria, aunque no emplea ilicitud directa y literal para alcanzar tal objetivo, utilizándose, para tanto, de estructuras no tipificadas o vedadas por la legislación vigente.

La doctrina anglosajona, también acentúa la diferenciación entre evasión y elusión, siendo la primera relacionada a la tax evasion, marcada por el acto de "huir del tributo", y, la segunda consagra por el término tax avoidance, o sea, el acto que busca "evitar el tributo"16.

No obstante, la clasificación de actitudes ilícitas a partir de la ley conceptuada como evasión fiscal no generaren grandes discusiones, la conceptuación del ámbito y regularidad de la llamada elusión fiscal provoca desacuerdos hasta la actualidad, que surgen principalmente de las posiciones teóricas alrededor de la interpretación del derecho tributario.

La llamada Teoría de la Elusión se divide entre el conceptualismo (positivismo normativista) que defiende, con base en la autonomía de la voluntad, la posibilidad ilimitada del planeamiento fiscal ${ }^{17}$ y la consideración económica del hecho imponible (positivismo sociológico), que a su vez llega a la conclusión opuesta, defendiendo el abuso de la forma como característica de la conducta jurídica elegida por el contribuyente que adopta estructuras jurídicas con la simple finalidad de ahorro tributario ${ }^{18}$, mismo que antecedente al eventual hecho imponible.

\footnotetext{
${ }^{15}$ Paulo Caliendo aporta una perspectiva única sobre el tema: "A evasão fiscal denota uma conduta que ofende a moralidade tributária, na medida em que se constitui em fuga ao dever de contribuir à manutenção de uma esfera de liberdade e igualdade. (...) A evasão fiscal ofende o princípio constitucional da livre concorrência, visto que opõe os contribuintes em situações diversas de competitividade de seus deveres e penalizando, no mercado, aqueles que se esforçam em estar em dia com seus deveres. A isonomia é igualmente prejudicada, na medida em que somente parte dos contribuintes irá cumprir um ônus que deveria ser dividido entre todos. " CALIENDO, Paulo. Direito Tributário e Análise Econômica do Direito: uma visão crítica. Rio da Janeiro: Elsevier, 2009. p.236.
}

\footnotetext{
${ }^{16}$ En ese sentido: "Todavia, a mais elementar distinção entre elisão e evasão fiscal ensina que a elisão é não entrar na relação jurídica tributaria e a evasão é dela tentar sair através da subtração ou diminuição de tributo devido. Tal distinção é bastante clara, alias, na língua inglesa, que consagra os termos tax avoidance (ato de evitar o tributo) para a elisão fiscal tax evasion (ato de fugir do tributo) para a evasão fiscal. A elisão fiscal se dá, necessariamente, antes de que ocorra qualquer fato qualificado pela lei como fato gerador e tributo.” TROIANELLI, Gabriel Lacerda. Comentários aos novos dispositivos do CTN: A LC 104. São Paulo: dialética, 2001. p. 41.
}

${ }^{17}$ Siendo por lo tanto la Elusión invariablemente lícita del punto de vista tributario. En este sentido DÓRIA, Antônio Roberto Sampaio. Elisão e Evasão Fiscal. São Paulo: Bushatsky, 1977.

\footnotetext{
${ }^{18}$ Para diferenciación entre simulación (relativa, absoluta y por interposición), fraude a la ley, abuso de derecho negocio jurídico indirecto, véase: YAMASHITA, Douglas. Elisão e Evasão de Tributos. Planejamento Tributário: Limites à Luz do Abuso do Direito e da Fraude à Lei. p. 293-305.; BIANCO, João Francisco. Transparência Fiscal Internacional. p. 108-116.; LAPATZA, José Juan Ferreiro. Curso de derecho financiero español. 25 ed. - Barcelona: Marcial Pons, 2006. p. 314-320.
} 
En este contexto, aquella inicial licitud generalizada de la Elusión, empieza a ser evaluado de nuevo por 3 escuelas distintas: i) Aquella que mantiene la licitud generalizada en el concepto de Elusión ${ }^{19}$; ii) Aquella que defiende una subdivisión en su campo de aplicación, considerando ciertas actitudes como lícitas y otras como ilícitas; y iii) La doctrina más Estadista que defiende a la ilicitud generalizada de la conducta elusiva.

Actualmente, delante del llamado Estado Social, son muy raros los defensores de la aplicación literal de la norma tributaria, hay una amplia aceptación de la posibilidad del Estado inserir en su ordenamiento previsiones legislativas que permitan a la administración pública y judicial relativizar la forma, cuando esta no está relacionado con la materialidad.

Otra parte de la doctrina y jurisprudencia propone, dentro del extenso campo de la licitud aparente, la incorporación del concepto de abuso del derecho tradicionalmente adoptado por el derecho civil, como norma secundaria de evaluación de la regularidad del comportamiento del contribuyente. En otras palabras, además de no caracterizar ilícito en su antecedente, la conducta no podría concretizar abuso de derecho en su consecuente.

Para mejor conceptuar esta subdivisión, la doctrina de los países anglosajones se utiliza de diferentes expresiones como "abusive tax avoidance" para caracterizar la elusión ilícita, en oposición a la "tax planning", "tax minimization" o "acceptable tax avoidance".

La tercera escuela, aboga por una planificación que tiene el objetivo de reducir el crédito tributario debido a determinado Estado, debe ser encarada como ilícita pues es atentatoria al interés público y, por lo tanto, no podría subsistir a la pretensión recaudatoria 20 .

Modernamente, tal vez en el intento de apartar algunas divergencias conceptuales y lingüísticas ${ }^{21}$, algunos estudiosos proponen la clasificación de la conducta del contribuyente en Evasiva, Elisiva y Elusiva; esta última definición abarcaría aquellos casos caracterizados por el abuso de forma, mientras la Elusión continuaría comprendiendo aquel planeamiento considerado lícito ${ }^{22}$.

${ }^{19} \mathrm{Al}$ considerarse la clasificación inicial binaria emanada por los conceptos de evasión y elusión, todo aquello que no era ilícito (en su sentido positivo normativista), estaría comprendido en el concepto de Elusión.

${ }^{20}$ La doctrina italiana, por ejemplo, entiende que la elusión es siempre ilícita: La distinción entre elusión lícita (elusión elecita) y elusión ilícita (elusión eillecita) es un "non senso" porque el fenómeno elusivo, correctamente individualizado, es siempre ilícito. En el caso en que no exista norma de contraste que sea violada no se puede hablar en elusión. ADONNINO, Pietro. Parecere del Ministero delle finanze e del Comitato Consultivo per l'aplicazione delle norme antielusive e rilevanza penale dell'elusione. Rivista di Diritto Tributario XI (2). Roma, 2001

${ }^{21}$ Tenga en cuenta, que la doctrina española, en virtud de su legislación pertinente (LGT), emplea el término "elusión", pero no en el mismo sentido que se describe en este apartado, sino como lo que la doctrina brasileña se entiende por "elisão" en este sentido, afirma Novoa: "elusión como opuesto a evasión. (...) es frecuente el uso del término elisao, entendido como la búsqueda, a través de instrumentos lícitos, de fórmulas negociales menos onerosas desde el punto de vista fiscal, a través, normalmente, de la elección de alternativas negociales. Aunque la doctrina brasileña diferencia elisao de economía fiscal, en tanto que la primera hay que reputarlo no querida por el legislador, ambas figuras partirían de la existencia de una 'laguna' o imperfección en el sistema tributario." p. 30.

22 Marcelo Costenaro Cavali, también menciona la elusión, definiéndola como: “(...) conduta levada a efeito pelo particular, consubstanciada na prática de atos ou negócios jurídicos distintos daqueles previstos em hipóteses de incidência tributaria, mas geradores de efeitos econômicos equivalentes, evitando dessa forma, a tributação, ou 
La doctrina española considera que las situaciones que se presentan desde el punto de vista de la Economía de Opción, que a su vez se basa en la idea de que la planificación se caracteriza por actividades lícitas que no contravengan el interés público, debe basarse en la opción prevista expresa en ley, y que implique en una carga tributaria más amena.

enquadrando-se em norma de tributação mais favorável." Veamos aun su abordaje a la evasión y elusión fiscal: "Definese assim, a evasão tributária, como a conduta realizada com o intuito de não pagar ou pagar menos tributos, nomeadamente impostos, caracterizada pela ilicitude dos atos praticados. (...) valemo-nos do termo evasão, no sentido de obtenção de diminuição da carga tributaria mediante a prática de atos ilícitos, destinados a esconder a realização ou adulterar a apresentação de fatos fiscalmente relevantes."; "A elisão tributária, assim, por vezes, deriva de situações previstas pelo legislador como aptas à concessão de um tratamento tributário mais benéfico ao contribuinte que, para tanto, deve adequar seu comportamento à norma. "Cláusulas Gerais Antielusivas: reflexões acerca de sua conformidade constitucional em Portugal e no Brasil. p. 26-30;

También haciendo uso de la triple conceptualización relativa a la planificación tributaria, Caliendo así dispone: "Como já verificado, a organização dos negócios privados pode ser realizada de três modos, mediante: elisão, evasão e elusão do dever de pagar tributos. O primeiro modo, elisivo, constitui conduta do contribuintes em organizar seus negócios de modo a, mantendo a 'causa' do negocio, reduzir seu efeito fiscal. Nesse caso, o contribuinte cumpre a legislação fiscal, mas impede ou modifica o modo de incidência da norma tributária, trazendo conseqüências fiscais (redução da carga tributária). Na evasão ocorre o descumprimento direto da norma impositiva, constituindo crime tributário. Havendo a incidência da norma tributária é necessário o seu cumprimento. Trata-se de uma organização ilícita dos negócios privados. Na elusão, a organização dos negócios privados ocorre mediante a utilização de estruturas negociais válidas que impeçam o surgimento da norma jurídica. A elusão, diferentemente da elisão, realiza-se em fraude ou abuso ao ordenamento jurídico tributário." CALIENDO, Paulo. Direito Tributário e Análise Econômica do Direito: uma visão crítica. Rio de Janeiro: Elsevier, 2009. p. 241-242. 
El profesor Ferrero Lapatza refuerza tal entendimiento ${ }^{23}$, relacionando tales actos a la elusión fiscal, contraponiéndose a los actos ilícitos sea el incumplimiento de previsión expresa, sea por aquello que considera simulación ${ }^{24}$.

Ponderados los posicionamientos doctrinarios nos parece, por lo tanto, que la definición de los límites a la libertad de planeamiento conferida al contribuyente no se desvía de la problemática de la búsqueda del concepto de Renta, abordada en los ítems precedentes.

Mejor explicando, aunque didácticamente exista la tentativa de separar o compartimentar especies de conducta, para fines de imposición tributaria, la posibilidad (o no) de tributación directa o desprecio de actos para la posterior tributación, con base en la sustancia y no en la forma solamente puede ser definida por ley.

En otras palabras, la respuesta si la planificación tributaria está restricta a "opciones" previstas expresamente, o deriva de la amplia libertad desde que no contraríe las normas vigentes, recae nuevamente sobre el legislador estatal, que definirá lo que es lícito o lo que es ilícito ${ }^{25}$

\footnotetext{
${ }^{23}$ En este sentido, el Profesor refuerza que la elusión fiscal indubitablemente se vincula al principio constitucional de la libertad: "La libertad de actuación en un mercado libre y la libertad negocial no son más que campos en los que se concreta y hace efectiva libertad como clave de bóveda de nuestro techo constitucional. (...) En este sentido, y ya en el ámbito de los tributos, debemos insistir en que - como tantas veces se ha dicho ya -, dentro de las actuaciones lícitas y libres de todo ciudadano, la elección y realización de un negocio, acto, contrato u operación económica válida, lícita y real es jurídicamente intachable, aunque se haya elegido, en comparación con otras, por su resultado equivalente y su menor o nula carga fiscal. Estamos aquí - clara y rotundamente - en el campo de las economías de opción. " p .311.; César García Novoa también admite la economía de opción, mejor denominada de planificación fiscal: "Pero la propia elusión linda, por otra parte, con el derecho de los individuos a desplegar sus actividades económicas, buscando, como dice Rosembuj, sus opciones de eficiencia, lo que se suele denominar economía de opción, ahorro fiscal o, mejor, planificación fiscal.” p. 36 ;
}

Al entrar en la cuestión y conceptualización de la evasión: "La posibilidad que tiene el contribuyente de acudir a la planificación fiscal, esto es, de optar dentro de la legalidad por las fórmulas fiscales más beneficiosas, parece una obviedad. Pero es una obviedad que se debe recordar, sobre todo, teniendo en cuenta el cariz de algunas reformas legislativas.” p. 102.; En que pese al expuesto, el Autor demostró que esta opción debe considerarse la legitimidad de la lucha contra la elusión fiscal, vez que tal combate está igualmente pautado en principios constitucionales como la capacidad contributiva y la solidaridad en el financiamiento de gastos públicos, veamos: "La legitimidad constitucional de la lucha contra la elusión fiscal y su reconocimiento como expresión de un interés público parece, en principio, evidente, la Administración puede y debe atacar la violación indirecta de las leyes tributarias exactamente igual que la defraudación fiscal. Y el TC ha venido legitimando la lucha contra el fraude de ley en la necesaria 'solidaridad de todos en el sostenimiento de los gastos públicos'. (...) La lucha contra la elusión fiscal, entendida en el sentido figurado de 'violación indirecta de la norma tributaria', sólo puede tener su justificación constitucional en el principio de capacidad económica como presupuesto del deber de contribuir y en la exigencia de un sistema tributario justo, inspirado en la igualdad y generalidad (art. 31.1 CE)’’. p. 98-102.; El brasileño Marciano Buffon, hace interesante ponderación bajo un prisma más próximo del expuesto por Novoa, abarcando aun un aspecto moral (aceptación social en la evasión por los brasileños) del combate a la evasión, resaltando la idea de la ciudadanía fiscal, pues la evasión proporciona desequilibrios económicos suportados por toda la sociedad. Para profundizar, véase: BUFFON, Marciano. Tributação e dignidade humana: entre os direitos e deveres fundamentais. Livraria do Advogado: Porto Alegre, 2009. p. 104-108.

\footnotetext{
${ }^{24}$ Para la diferenciación entre simulación (relativa, absoluta y por interposición), fraude a la ley, abuso de derecho y negocio jurídico indirecto, véase: YAMASHITA, Douglas. Elisão e Evasão de Tributos. Planejamento Tributário: Limites à Luz do Abuso do Direito e da Fraude à Lei. p. 293-305.; BIANCO, João Francisco. Transparência Fiscal Internacional. p. 108-116.; LAPATZA, José Juan Ferreiro. Curso de derecho financiero español. 25 ed. - Barcelona: Marcial Pons, 2006. p. 314-320.

25 "Cada ordenamento jurídico que a adota, pode fundamentar sua cláusula geral antielusiva em conceitos e institutos diversos. Pode-se valer da aproximação com o abuso do direito ou a fraude à lei, prevendo pressupostos de aplicação e
} 
Tal norma, comúnmente denominada Norma General Antielusiva, presenta estructura y amplitud variada conforme el Estado que la adopta, aunque siempre con el objetivo de definir en qué casos la Administración Pública puede interferir en la esfera privada con fines recaudatorios ${ }^{26}$.

\section{Reglas de Precios de Transferencia}

En el ámbito de las transacciones internacionales analizadas en este estudio, ciertas especies generan la especial atención de los Estados; son aquellos en que se verifica cierto grado de vinculación entre las partes que lo componen.

La preocupación por la transferencia de ingresos o bienes a las jurisdicciones fiscalmente más beneficiosos o, incluso la generación de costos y gastos deducibles por parte de otras sociedades controladoras o coligadas a esta primera sociedad, puede viciar transacciones mercantiles, creando condiciones artificiales de precios y costos que perjudicarían la libre competencia y la igualdad de condiciones entre las empresas del mismo sector (arm's length ${ }^{27}$ ).

consequências jurídicas distintos dos estabelecidos no direito privado, ou pode criar figuras novas, como o abuso de formas jurídicas, a necessidade de interesse negocial (business purpose test) etc. (...)” CAVALI, Marcelo Costenaro. Cláusulas Gerais Antielusivas: reflexões acerca de sua conformidade constitucional em Portugal e no Brasil. p. 118.

26 'Para o reconhecimento da norma evitada (ou eludida), a cláusula geral antielusiva utiliza um 'elemento de conexão'em regra, refere-se à 'equivalência de efeitos econômicos'. Assim para saber qual a norma autônoma (regra matriz de incidência) a que a norma eludida está quase sempre evidente aos olhos do aplicador. É esta norma que, em função da atuação da clausula, produzira seus efeitos dando nascimento à obrigação tributária como se o fato nela previsto tivesse ocorrido diretamente." CAVALI, p. 122.

27 "Tiene por finalidad tratar a los distintos miembros de un grupo multinacional como se operaran como empresas separadas en lugar de cómo partes inseparables de una sola empresa unificada. Este principio de entidad independiente o entidad separada, separate entity approach, es un pilar en el desarrollo del principio de libre concurrencia. Se ha considerado que este principio ofrece un tratamiento fiscal equitativo entre empresas multinacionales y empresas independientes y evita que surjan ventajas desventajas fiscales que, de otra forma, distorsionarían su posición competitiva relativa en el mercado." VILADOMAT, Montserrat Trapé. El régimen Fiscal de los Precios de Transferencia. In: EZQUERRO, Teodoro Cordón (dir.). Manual de Fiscalidad Internacional. $2^{a}$ ed. atual. e rev. - Madrid: Instituto de Estudios Fiscales, 2004. p. 445.

Desde la perspectiva de La OCDE, el tema versado por el artículo $9^{\circ}$ y su modelo de convención sobre renta y patrimonio. Por consiguiente, este artículo establece que delante de empresas asociadas ("controladora y subsidiarias y sociedades bajo control común") - Modelo de Convenção Tributária sobre o rendimento e o Capital, versión condensada al portugués de julio de 2010, p. 189.), sus lucros deben ser ajustados para efectos del impuesto cuando no operan bajo el principio de arm's length, si, al igual que las empresas independientes, gobernados por las fuerzas del mercado, y que a continuación, simular artificialmente tales fuerzas, aunque no sea atingido como multinacional, como si esas actuasen sobre su operación, aproximando así las empresas asociadas e independientes de una libre competencia, por lo tanto, con la observancia de la arm's length. Las conclusiones de la OCDE sobre el tema fue objeto del informe: Transfer Pricing Guidelines for Multinational Enterprises and Tax Administration (original de 2005, siendo su última versión en 22/07/2010). Sigue su introducción al tema: "(...) the arm's length principle, which is the international transfer pricing standard that OECD member countries have agreed should be used for tax purposes by MNE groups and tax administrations. (...) When independent enterprises transact with each other, the conditions of their commercial and financial relations (e.g. the price of goods transferred or services provided and the conditions of the transfer or provision) ordinarily are determinated by market forces. When associated enterprises transact with each other, their commercial and financial relations may not be directly affected by external market forces in the same way, although associated enterprises often seek to replicate the dynamics of market forces in their transactions with each other (...). When transfer pricing does 
Cuando medidas de control y ajustes de estas transacciones son realizados unilateralmente por Estados con el fin de restablecer el equilibrio de esta transacción con relación al mercado, se da el nombre de Precio de Transferencia (transfer pricing) ${ }^{28}$.

Por lo tanto, este instituto está directamente vinculado a los acuerdos para compartir los costes (costs sharing agreements) que componen la planificación de la asignación de los costes y el reconocimiento de los beneficios utilizados por grupos internacionales y que actúa a través de las previsiones legalmente establecidas, que adoptan métodos de ajustes en el valor de las operaciones, basándose en referenciales mercadológicos vigentes en la época, sean ellos relativos a operaciones de venta o transferencia (de bienes, servicios o intangibles) ${ }^{29}$.

Históricamente, la adopción de metodologías de ajustes a las operaciones entre empresas vinculadas, tiene sus raíces en la década de 1930, cuando muchos Estados empezaron las incorporaciones de estas medidas en su legislación tributaria.

Pero, fue a partir de 1979, cuando la OCDE pasó a difundir entre sus miembros la necesidad de adopción de tales ajustes que el instituto de los precios de transferencia tuvo gran difusión culminando en la elaboración de una serie de directivas, que en las décadas siguientes fueron consolidadas en el informe titulado "OECD Transfer Pricing Guidelines for Multinational Enterprises and Tax Administrations".

A este informe se han hecho actualizaciones en 1984,1987 y 1995, cuando empezó a tener la siguiente estructura: el Capítulo I pretendió establecer una igualdad de condiciones para la competencia en el mercado, como una herramienta esencial para las evaluaciones consistentes en varias administraciones; el capítulo II y III tratan de los llamados "métodos tradicionales de determinación de precios de transferencia ("Los métodos tradicionales basados en operaciones ") y de los otros métodos demostrando la distribución de beneficios y margen bruta para todas las operaciones.

not reflect market forces and the arm's length principle, the tax liabilities of the associated enterprises and the tax revenues of the host countries could be distorted." OECD (OECD, 2010). p. 31-32

${ }^{28}$ El Profesor Luís Eduardo Schoueri, aborda el tema en profundidad en su obra: Preços de Transferência no Direito Tributário Brasileiro, sigue sus ponderaciones: "Por preço de transferência entende-se o valor cobrado por uma empresa na venda ou transferência de bens, serviços ou propriedade intangível, a empresa a ela relacionada. Tratando-se de preços que não se negociaram em um mercado livre e aberto, podem eles se desviar daqueles que teriam sido acertados entre parceiros comerciais não relacionados, em transações comparáveis nas mesmas circunstâncias. (...) Neste sentido, cabe ponderar em que cenário se insere a legislação de preços de transferência. Trata ela de transações entre parte vinculadas. Estas transações diferenciam-se daquelas praticadas por partes independentes pela ausência do mercado como árbitro da distribuição de riquezas. Com efeito, num mercado em que as partes independentes relacionam-se comercialmente, é razoável admitir que cada qual busca trazer para si as maiores vantagens possíveis e que da tensão dialética que exsurge a cada transação resulta um preço, denominado 'preço de mercado', que nada mais é do que o parâmetro para distribuir a riqueza (ou renda) entre as partes." p. 10-12.

29 'En efecto, el Derecho comparado y la doctrina cientifica denominan 'precios de transferencia' (transfer pricing) a aquellos que utilizan y pactan entre sí sociedades sometidas al mismo poder decisión, con el fin de permitir y conseguir, a través de la fijación de tal clase de precios convenidos entre ellas, el transferir o traspasar beneficios o pérdidas de unas a otras - situadas, en muchas ocasiones, en paises distintos.” ARMENGOL, Albert Collado; PACHECO, Abelardo Delgado; ESTESO, Ramón López de Haro. Pasado, Presente y Futuro del régimen de los precios de transferencia en España. In: ANTÓN, Fernando Serrano. Fiscalidad Internacional. 2a ed. rev. y ampl. Madrid: Centro de Estudios Financieros, 2005. p. 483. 
Capítulo IV analiza los procedimientos administrativos destinados a prevenir y resolver los litigios relativos a los precios de transferencia (Acuerdos previos sobre los precios- APA), así como acuerdos para arbitraje entre Estados y Estados y contribuyentes, y el capítulo $\mathrm{V}$, trata de los documentos validos para fines de los acuerdos.

En su actualización final, en 1996, han incluido tres capítulos más: Capítulo VI para reglamentar las cuestiones relativas a la aplicación de la evaluación de los activos intangibles; el capítulo VII, sobre aspectos específicos de los servicios entre empresas relacionadas o subsidiarias, y el Capítulo VIII, que trata de los acuerdos de división de los gastos.

Dichos informes, en general, sugieren métodos para la evaluación de los precios de las transacciones entre empresas asociadas, comparándolas con las transacciones con terceras partes o de otras sociedades del grupo, y también establece excepciones que intentarían la remoción de la aplicación de los ajustes.

Sin embargo, el instituto se basa, sobre todo, en garantizar la igualdad de desarrollo de actividades empresariales, la finalidad de la aplicación de precios de transferencia es claramente la protección de la recaudación de impuestos por los estados, no abarcando políticas antidumping o de combate a los recargos estatales ${ }^{30}$.

Así, el lucro contable de una empresa ubicada en el territorio nacional puede ser ocasionalmente otra vez evaluado de forma que se aproxime a un lucro mediante la adopción de precios de mercado, más cerca de la realidad de sus competidores, sin grandes distorsiones causadas por la conexión de empresas que seguramente podrían atribuir costos o precios artificialmente considerados, colocándolas en desigualdad con relación a sus competidores independientes. ${ }^{31}$

\footnotetext{
30 "O instituto, hoje, integra-se dentre as práticas adotadas pelos Estados com o fito de coibir que entidades consideradas como relacionadas, consoante critérios previstos em lei, transfiram riqueza, sob a forma de rende tributável, de um país para outro, com a finalidade de reduzir ou eliminar o correspondente encargo tributário. As regras de preço de transferência objetivam regular, para fins tributários, os preços praticados nos negócios comerciais, voltados à importação e exportação de bens, serviços, direitos, bem como aos juros adotados em contratos internacionais, entre partes relacionadas.” BIFANO, Elíede Palma. Apuração de Preços de Transferência em Intangíveis, Contratos de Prestação de Serviços, Intragrupo e Cost Sharing Agreements. In: Schoueri, Luís Eduardo (coor). Tributos e Preços de Transferência. $3^{\circ}$ v. São Paulo: Dialética, 2009. p. 28.

31 “Assim, entende-se que ao substituir os preços das transações entre partes ligadas pelos preços de mercado, a legislação sobre preços de transferência nada mais busca senão aferir com maior exatidão a riqueza gerada pela empresa. A luz do conceito de renda, portanto, a legislação sobre preços de transferência será aceita - e até exigida - quando, privilegiando os preços de mercado, apurar com exatidão a renda tributável. Em consequência, apenas se tolera a substituição dos preços praticados em uma transação se, sem eu lugar, se registrarem valores que representam com maior exatidão os preços de mercado. (...) Assim, pode-se dizer que enquanto a moeda constante nas contas das empresas com transações controladas está expressa em unidades 'reais de grupo', empresas independentes têm seus resultados expressos em 'reais de mercado'. Nesta perspectiva, o papel da legislação de preços de transferência é apenas, 'converter' valores expressos em 'reais de grupo' para 'reais de mercado', possibilitando, dai, uma efetiva comparação entre contribuintes com igual capacidade econômica. Neste sentido, verifica-se a legislação de preços de transferência não distorce resultados da empresa. Apenas 'converte' para uma mesma unidade de referência ('reais de mercado') a mesma realidade expressa noutra unidade." SCHOEURI, Luís Eduardo. Preços de Transferência no Direito Tributário Brasileiro. 2a ed. rev. e atual. São Paulo: Dialética, 2006. p. 12-15.
} 


\section{Exit Tax}

También vale la pena mencionar el llamado impuesto de salida, también comprendido como impuesto de expatriación (exit tax, departure tax o repatriation tax) ${ }^{32} \mathrm{lo}$ cual se incide sobre las personas físicas o jurídicas que transfieren sus domicilios para otro país, o aun, que renunciarán su ciudadanía (caso comportado solamente por personas físicas - los llamados expatriados) al transfirieren su domicilio.

La discusión sobre el tema ha ido ganando contornos actuales y se asientan bajo distintos aspectos, entre los que podemos suscitar: una percepción en el ámbito de una posible elusión fiscal, un examen a partir da expatriación, está considerada como un derecho fundamental de forma que una imposición tributaria seria ilegítima por ofender, con base en la nacionalidad, el derecho fundamental de locomoción, o aun, el principio de la libertad de establecimiento previsto en el Tratado de la Unión Europea.

Desde el punto de vista de la elusión fiscal, podemos suscitar la reciente discusión sobre un nuevo fenómeno, visto sobre todo en los EUA, lo que ha llevado a las personas a renunciar a su ciudadanía con el fin de evitar la incidencia tributaria que adopta la nacionalidad como criterio residual de la incidencia.

Esta práctica se difundió ampliamente en el caso de Eduardo Saverin, brasileño cofundador de la rede social Facebook, que renunció su ciudadanía estadunidense visando desvincularse del FISCO norte americano. ${ }^{33}$

Por otro lado, la discusión bajo el aspecto de la discriminación ganó impulso con el estudio de William Thomas Worster, profesor y abogado, que analizando el régimen fiscal norte americano conferido a expatriados, afirma que tal tratamiento representa verdadera afronta a los principios de protección igualitaria por conferir a extranjeros tratamiento más penoso de forma injustificada, por el simple hecho de conseguir exprimir intereses del gobierno cuando de la aplicación del impuesto. Por otra parte, el autor entiende que, la manera como ocurre la imputación viola el principio fundamental del proceso legal debido. ${ }^{34}$

\footnotetext{
${ }^{32}$ Forma voluntaria de extinción de la ciudadanía.
}

${ }^{33}$ Curioso es el tratamiento que el gobierno estadunidense da a la situación, afirmando que los inmigrantes son considerados verdaderas "máquinas de dinero", conforme el propio informativo de la inmigración americana. En los Estados Unidos, referido impuesto fue creado en 2008 por el conocido Heroes Earnings Assistance and Relief Tax Act of 2008 (Heart Act), con previsión de alícuota que puede llegar a $30 \%$.

${ }^{34}$ Presentamos la conclusión de Worster: "Based on the fact that expatriation is a fundamental right and that the expatriation tax discriminates on the basis of national origin, the tax provisions demand strict scrutiny analysis. In applying strict scrutiny, we cannot find any compelling government interest to justify the tax provision, and even if a satisfactory justification could be found, the tax provision is not narrowly tailored to achieve the justified end. Accordingly, the expatriate tax provisions as they current stand do not satisfy the requirement of equal protection and due process of law. If the tax provisions were to be brought into conformity with equal protection and due process, then when a person expatriates, the person simply becomes an alien and falls into the general non-resident alien, non-U.S. person, category and would acquire U.S. residence only through the normal operation of the IRC measuring residence, just as any other alien would. Essentially, the person's former citizenship would be completely ignored and the person treated as a citizen 
Cuanto a la limitación de la movilidad humana, se entiende que, aunque no haya un derecho de movilidad aun no reconocido internacionalmente, dentro de la Comunidad Europea, un impuesto de salida cobrado desproporcionalmente puede ser considerado como limitador, por fuerza de interpretación dada por la Corte Europea de Justicia (ECJ) del artículo 49 del Tratado sobre el Funcionamiento de la Unión Europea (TFUE) a partir del caso European Commission v Kingdom of the Netherlands (Case C-301/11) juzgado en $31 / 01 / 2013$.

Anticipándose a esta decisión, la Comisión Europea ya en 2008 había denunciado España ante la Corte (ECJ), afirmando que la legislación española (The Spanish Corporate Tax Act) está en desacuerdo con las reglas vigentes en la Comunidad Europea, una vez que el impuesto de salida cobrado de las empresas, constituye verdadera penalidad a ellas, afrontando el principio da la libertad de establecimiento.

El caso C-301/11se respalda en el hecho de que el Artículo 17, apartado 1, de la LIS - Ley del Impuesto sobre Sociedades) comprende como renta imponible o ganancias de capital (aún que no realizadas) imponibles, los siguientes movimientos:

i) Propiedad de una entidad domiciliada en España que se traslada para fuera de España ${ }^{35}$

ii) Propiedades atribuibles a un Establecimiento Permanente que encierra sus actividades;

iii) Propiedades atribuibles a un Establecimiento Permanente que se mueve fuera de España.

El Tribunal de Justicia Europeo (TJCE) ha entendido que la primera y tercera hipótesis arriba mencionadas restringen la libertad de establecimiento prevista en el artículo 49 del Tratado de Funcionamiento de la Unión Europea, cuando el país de acogida es un miembro de la UE, determinando su cambio.

En respuesta a la decisión del Tribunal de Justicia, la Ley de Presupuesto de 2014 establece que, cuando la entidad Española o establecimiento permanente traslada su domicilio a un país de la UE, la tasa de salida (exit tax) podrá ser diferida hasta que estos activos sean vendidos o transferidos a otra entidad. Esta modificación se aplica con carácter retroactivo al año fiscal de 2013 y se aplican también a los intereses que advengan de estos activos durante el período de desplazamiento.

only of the state in which the person held citizenship at the time. Unrealized gain would still be taxable, only at the rate normally applied to all nonresident aliens. This method of taxation goes to heart of what it means to be a citizen. Is a citizen simply an individual receiving benefits from the legitimate monopolizer of violence or is the citizen a member of a common endeavor to create and sustain a government among equals? If the people are the former, existing in a separated and adversarial relationship with the government, then perhaps the government should be empowered to tax all who it can reach for its own enrichment. If, on the other hand, the citizens are engaged in a collective relationship, with the government merely acting as their representative and agent, then when a citizen elects to leave the community and no longer receive the rights of the community, then the individual should not have lingering obligations upon leaving the state. "WORSTER, William Thomas Worster. The Constitutionality of the Taxation Consequences for renouncing U.S Citizenship.

${ }^{35} \mathrm{~A}$ menos que los activos sean de son atribuibles a una empresa pública española, 


\section{El Crédito de tributo atribuido unilateralmente}

El reconocimiento unilateral de crédito de tributo pagado a otro Estado como resultado de las actividades internacionales es norma de tributación internacional, comúnmente encontrada desde el siglo XIX, cuando Alsacia Lorena comenzó a reconocer en la tributación de las sucesiones, eventuales tributos pagados en otros Estados como crédito pasible de abatimiento en el tributo debido.

Actualmente, la mayoría de los países se utiliza de dos métodos de reconocimiento de tributos pagados en el exterior para fines de reducción en la recolección de tributos internos, sean, Tax exemption, Tax Credit (La doctrina mayoritaria adopta la división entre tax exemption y tax credit, abarcando la tax sparing como una de las posibilidades de tax credit, sea full o ordinary, o al lado del matching credit) ${ }^{36}$.

Como se deduce del propio nombre, la Tax exemption ${ }^{37}$ instituida unilateralmente tiene por finalidad impedir el nacimiento de la obligación tributaria o evitar la exigibilidad de la obligación tributaria generada.

Exención tiene dos formatos, la exención total (full exemption), y la exención progresiva (progressive exemption). La primera se produce cuando el valor del tributo recolectado en el extranjero siquiera es tomado en cuenta para cualquier propósito, lo que exime, de inmediato, al contribuyente de la obligación de recolectar cualquier impuesto.

En la segunda, el tipo de rendimiento tributado y su montante, se tiene en cuenta para efectos de fijación de alícuota progresiva para la renta global de la persona física o jurídica, en respecto aquella parcela especifica no tributada, juntamente con los demás rendimientos frente a la exención conferida a los rendimientos internacionales ${ }^{38}$.

\footnotetext{
${ }^{36}$ Véase: ANTÓN, Fernando Serrano. Los principios básicos de la fiscalidad internacional y los convenios para evitar la doble imposición internacional: historia, tipos, fines, estructura y aplicación. . In: Fiscalidad Internacional. 2a ed. rev. y ampl. Madrid: Centro de Estudios Financieros, 2005. p. 221. "Desde el punto del método adoptado para evitar la doble imposición internacional se puede hablar de la siguiente clasificación: Método de exención, y Método de imputación."
}

\footnotetext{
${ }^{37}$ Resaltamos que conforme la doctrina española, la exención es instituto del derecho tributario que impide el nacimiento de la obligación tributaria. Sin embargo, la traducción literal a la lengua portuguesa puede causar imprecisiones, ya que, según el instituto de ordenamiento brasileño, el instituto capaz de impedir el nacimiento de la obligación tributaria es denominado "inmunidad" mientras "exención" significa que la obligación tributaria nació, pues hubo el marco perfecto del hecho jurídico a la regla matriz de imposición tributaria, aunque no sea exigible en función de determinado marco legal.

${ }^{38}$ La doctrina converge internacionalmente con respecto a la anterior: "O método da isenção comporta duas modalidades: ou o rendimento não é tido em consideração seja para que efeito for - e temos a isenção integral; ou o rendimento, apesar de não ser tributado, é tomado em consideração, conjuntamente com os de produção interna, para o efeito de determinar a alíquota progressiva aplicável à renda global - e temos isenção com progressividade, isenção qualificada ou método de alíquota efetiva. Claro que este método só é relevante caso o imposto no Estado da residência tenha caráter progressivo e não proporcional." XAVIER, Alberto. Direito tributário internacional do Brasil. $6^{\text {a }}$ ed. atualizada - Rio de Janeiro: Forense, 2004. p. 815-816.; "Na isenção dita integral ou pura (full exemption), o Estado abstém-se de submeter a qualquer imposição os elementos redituais de fonte estrangeira, excluindo-os da base de calculo dos impostos internos. Em termos de eficácia técnica, o método da isenção integral permite a priori evitar, de modo mais seguro, o fenômeno da bitributação internacional, na medida em que mantém os contribuintes que produzem renda no exterior submetidos a um único ordenamento impositivo (...). O outro método é o da isenção com progressividade (exemption avec progressivité), que, em breves termos, se trata da aplicação de um imposto progressivo condicionado pela isenção, por que a matéria tributável de fonte estrangeira ou situada no estrangeiro não entra na formação da base de calculo do imposto devido internamente, mas é levada em consideração para calcular o quantum debeatur de imposto, sob alíquota progressiva."
} 
El método de Tax credit, también llamado de crédito de impuesto, método de imputación ${ }^{39}$ o de deducción de impuesto, puede ser comprendido como la creación de un crédito a favor del contribuyente para que él pueda abatir valores ya pagados en el exterior referente al impuesto que también a él es debido en el Estado de su residencia ${ }^{40}$.

Tenga en cuenta que el importe Tax credit, en la práctica, en la no necesidad de recolección de cualquier tributo, aun así ello será diferente de la Tax exemption, justamente porque en esa, como ya hemos visto, no se aplica tributación, mientras que en el crédito de impuesto hay efectivamente tributación, aunque esta solamente incida sobre aquello que no fuese pagado en el Estado extranjero (obviamente que se requiere estar delante de tributos de naturaleza equivalente), creando así un crédito en el país de residencia de aquel que fue pagado en el exterior ${ }^{41}$.

\footnotetext{
39 "La imputación ha sido el método de los países angloamericanos. La característica principal es que este método consiste en que el país de residencia del inversor trata al impuesto pagado en el extranjero, con ciertas limitaciones legales, como si fuera un impuesto pagado al mismo." ANTÓN, Fernando Serrano. Los principios básicos de la fiscalidad internacional y los convenios para evitar la doble imposición internacional: historia, tipos, fines, estructura y aplicación. In: Fiscalidad Internacional. 2a ed. rev. y ampl. Madrid: Centro de Estudios Financieros, 2005. p. 223-224.; "O método da imputação, chamado também método do crédito ou de dedução do imposto, é o método destinado a evitar ou eliminar a dupla tributação por força do qual se deduzirão imposto pagável num Estado o imposto pago no estrangeiro. É, pois um método que opera sobre colecta, evitando ou eliminando a dupla tributação efectiva. Este método parte do princípio que os residentes com rendimentos do estrangeiro devem ser colocados em situação de igualdade ou em situação não mais favorável face aos que auferem rendimentos apenas do país. "PIRES, Manuel. Da dupla tributação jurídica internacional sobre o rendimento. Lisboa, Centro de Estudos Fiscais — Ministério das Finanças, 1984. p. 362.
}

40 “Cuando el impuesto pagado en el extranjero posee un tipo de gravamen inferior al del Estado de residencia, sólo el exceso de este último impuesto en relación con el pagado de la fuente es recaudado por el impuesto del país de residencia del inversor. Sensu contrario, cuando el impuesto de la fuente es más alto que el del Estado de residencia, este país no obtiene ningún ingreso por dicha renta. La efectiva carga fiscal global se determina por el tipo de gravamen más alto del Estado de la fuente o el de residencia." ANTÓN, Fernando Serrano. Los principios básicos de la fiscalidad internacional y los convenios para evitar la doble imposición internacional: historia, tipos, fines, estructura y aplicación. In: Fiscalidad Internacional. 2a ed. rev. y ampl. Madrid: Centro de Estudios Financieros, 2005. p. 223-224.

${ }^{41}$ De forma didáctica, Xavier versa así: "No método da imputação (tax credit), o rendimento de fonte estrangeira não é isento, de tal modo que o Estado da residência tributa a renda global do contribuinte, seja qual for a sua origem. Todavia, do montante do imposto assim apurado deduz (credita) o imposto pago no país da fonte, desde que este imposto seja de natureza equivalente ao imposto pago no país da residência. $O$ sistema de isenção considera a renda; o sistema de imputação, o imposto sobre a renda. 'XAVIER, Alberto. Direito Tributário Internacional do Brasil. 6 a ed. atualizada Rio de Janeiro: Forense, 2004. p. 819.; Además, Fernando Antón destaca que la cantidad adeudada en el país de residencia, sólo se centra en la diferencia entre lo que se ha pagado en el extranjero y lo que aún se debe en el país de residencia: "Cuando el impuesto pagado en el extranjero posee un tipo de gravamen inferior al del Estado de residencia, sólo el exceso de este último impuesto en relación con el pagado de la fuente es recaudado por el impuesto del país de residencia del inversor. Sensu contrario, cuando el impuesto de la fuente es más alto que el del Estado de residencia, este país no obtiene ningún ingreso por dicha renta. La efectiva carga fiscal global se determina por el tipo de gravamen más alto del Estado de la fuente o el de residencia." ANTÓN, Fernando Serrano. Los principios básicos de la fiscalidad internacional y los convenios para evitar la doble imposición internacional: historia, tipos, fines, estructura y aplicación. In: Fiscalidad Internacional. 2a ed. rev. y ampl. Madrid: Centro de Estudios Financieros, 2005. p. 223-224.; Aun, dos son las modalidades de tax credit: full credit (imputación integral o crédito de impuesto integral) y ordinary credit (imputación ordinaria o crédito de impuesto ordinario). En la primera, el país de la residencia del contribuyente deduce el valor total del impuesto pagado en el país extranjero fuente de la renta, mientras en el segundo solamente deducirá parte del importe total pagado en el exterior, observando una limitación de la deducción. Por fin, el crédito de impuesto, sea en su modalidad total o ordinaria, puede presentar algunas dificultades para su medición, y con el fin de sanar tales obstáculos se crearon dos modalidades ficticias que apoyan el cálculo del impuesto a pagar en la residencia del contribuyente: tax sparing (crédito ficticio) y tax matching (crédito presumido o pre fijado). Heleno Tôrres las denomina de "modalidades de mecanismos de corrección al crédito de impuesto." p. 464. En el crédito presumido hay una pre fijación que aumenta "ficticiamente" la 
Son dos las modalidades de tax credit: full credit (imputación integral o crédito de impuesto integral) y ordinary credit (imputación ordinaria o crédito de impuesto ordinario). ${ }^{42}$ En la primera, el país de residencia del contribuyente deduce el valor total del impuesto pagado en el país extranjero de la fuente de la renta, mientras en el segundo solamente se descuenta de la parte del montante total pagado en el exterior, observando una limitación al descuento; en otras palabras, mientras el primero permite el aprovechamiento total del crédito, el segundo permite el aprovechamiento del crédito solamente relativo aquella renta tributada en el exterior, siendo que, sí el tributo pagado sobre tal renta al otro Estado superar el tributo que debería ser pagado internamente, este exceso no podrá ser aprovechado para otras rentas obtenidas.

Los métodos de exención tributaria, denominados en ámbito internacional de tax exemption system se relacionan a la ausencia de imposición tributaria prevista legalmente. Sacha Calmon se acuerda que una norma puede ser dividida en hipótesis y consecuencia ${ }^{43}$. De modo que, la exención ${ }^{44}$ refleja la no ocurrencia de la consecuencia

alícuota del impuesto debido en el extranjero, para fines de cálculo del impuesto a ser pagado en el país de residencia. Ya el crédito ficticio establece un crédito en el país de residencia del contribuyente con relación al impuesto que sería debido en el extranjero, caso no hubiese beneficios fiscales promoviendo determinada exoneración (como acuerdos bi laterales, por ejemplo). Antón bien acentúa que en el primero caso no hay cualquier necesidad previa de vigencia de algún incentivo fiscal, mientras que en el último es pre-requisito: "Así, en el caso del Tax Sparing, el país de la residencia permite la imputación del impuesto que habría sido sufrido en el país de la fuente de no Haber existido un determinado incentivo. Su aplicación depende de la existencia de politica fiscal. Se trata de respetar los efectos de la renuncia hecha por el país de la fuente que de otro modo se anularía a favor del país de la residencia. En el caso del Matching Credit, el país de la residencia permite la imputación de un determinado porcentaje superior que el que correspondería aplicar al país de la fuente. No se trata entonces de respetar los incentivos otorgados por el país de la fuente, sino de una renuncia unilateral por parte del país de la residencia." p. 225.

42 “(...) En efecto, puede ocurrir que se haya acordado la deducción completa del impuesto pagado en el Estado de la fuente, lo que significa que se estaría en presencia del método de imputación íntegra (full credit). Asimismo, también puede ocurrir que se haya convenido que el crédito corresponda tan sólo a lo que se debería pagar por dichas rentas de ser obtenidas en el Estado de la residencia, o lo que es lo mismo método de imputación ordinaria (ordinary credit). " ANTÓN, Fernando Serrano. Los principios básicos de la fiscalidad internacional y los convenios para evitar la doble imposición internacional: historia, tipos, fines, estructura y aplicación. In: Fiscalidad Internacional. 2a ed. rev. y ampl. Madrid: Centro de Estudios Financieros, 2005. p. 224.

43“"De fato as leis desenham hipoteticamente inúmeros fatos ou aspectos fatuais, ligando-os a um determinado efeito jurídico, qual seja, o da incidência do imperativo tributário. Com fazer isso, as leis, uma, duas ou inúmeras, conjugadas, acabam por 'projetar' no espaço normativo o perfil da norma de tributação. Uma norma composta de hipótese (situações fáticas) e conseqüencias jurídicas." COÊLHO, Sacha Calmon Navarro. Teoria Geral do Tributo, da Interpretação e da Exoneração Tributária (O Significado do art. 116, parágrafo único, do CTN). São Paulo: Dialética, 2003. p. 199.

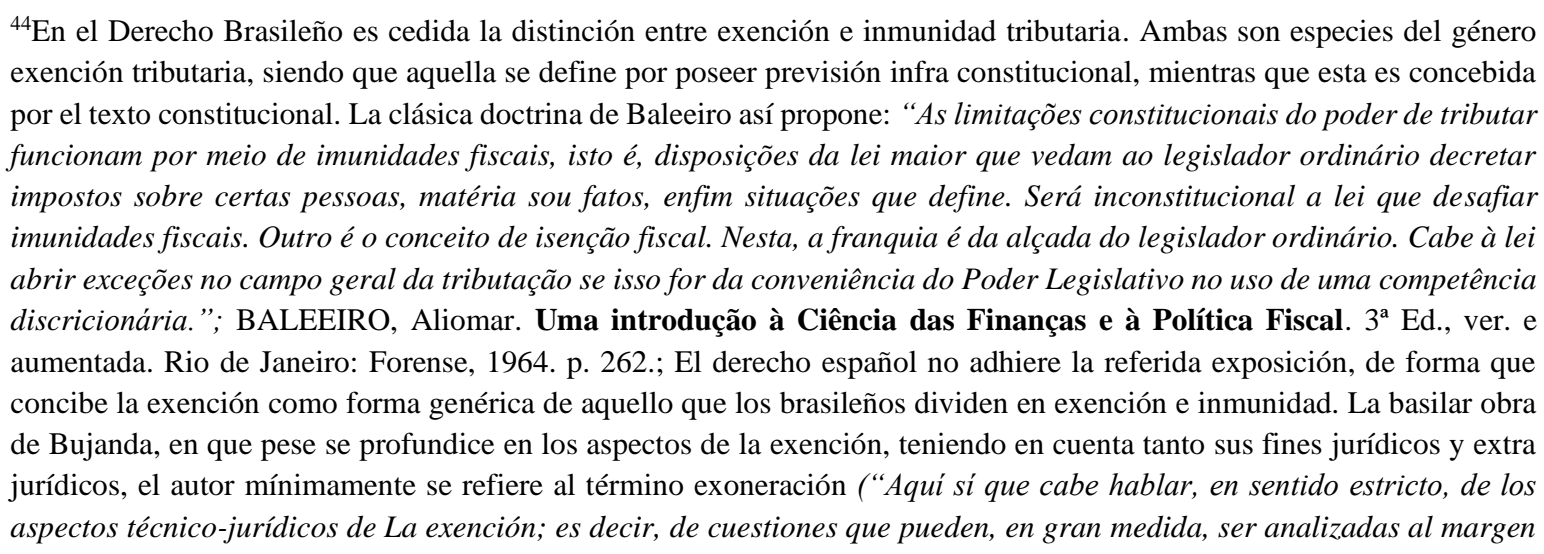


jurídica y no de la norma en sí mismo (hipótesis), pues la obligación tributaria nació de la realización del soporte fático previsto por la hipótesis de la norma, sólo no se desarrollando la imposición del imperativo tributario, que trajo la consecuencia jurídica que también compone a norma tributaria ${ }^{45}$.

En el ámbito internacional, se observa que las técnicas legislativas de exoneración, principalmente de exención, se aplican de manera idéntica a las exoneraciones internas, aunque sus requisitos presenten como requisito único o adicional a la presencia de un elemento de extranjería en la hipótesis de incidencia ${ }^{46} .0$ sea, tiene por finalidad "exentar del impuesto debido en el país de residencia los rendimientos de fuente extranjera" 47 .

Aun es necesario destacar que este tipo de norma comporta dos formatos ${ }^{48}$ : la exención total (full exemption) y la exención progresiva (progressive exemption). Lo primero ocurre cuando el rendimiento siquiera es considerado para cualquier efecto, mientras en el segundo, el rendimiento es observado, a pesar de no ser tributado frente a la exención

del fundamento que explique su existencia como exoneración de un deber de pago tributario. ” BUJANDA, Fernando Sainz de. Hacienda y Derecho. Estudios e Derecho Financiero III. Madrid: Instituto de estudios políticos, 1963. p. 392.), que, en realidad la doctrina española no hace mayores diferenciaciones en relación a los géneros del instituto de la exoneración tributaria. El profesor español hace fuerte ligación del instituto de la exención a la teoría jurídica del tributo, proponiendo, aun, en igual medida una teoría de la exención: "Parece, por tanto, indudable que si existe una teoría jurídica del tributo, también debe existir una teoría jurídica de la exención tributaria. Se trata, en rigor, de la misma teoría vista del enés." p. 394.

45 "As alterações que as leis tributárias provocam nas hipóteses das normas de tributação são qualitativas, porquanto, em última análise, qualificam ou desqualificam juridicamente os fatos (os fatos, então, são ou não aptos a 'gerar' tributação, se e quando ocorrentes). Ao revés, as alterações que as leis tributárias ensejam nas consequências das normas de tributação são quantitativas, por isso que afetam apenas o quantum do dever jurídico de pagar impostos: no primeiro caso, o efeito desqualificante que as leis provocam nos 'fatos jurigenos' impede a incidência do imperativo, e, pois, a norma de tributação não incide. Noutras palavras, não há obrigação. No segundo caso, os fatos jurígenos, por isso que não afetados por nenhuma lei imunizante ou isentante, quando ocorrem provocam a incidência do mandamento da norma de tributação. Há obrigação. Apenas as condições para cumprimento do dever tributário são alteradas para menos. Os efeitos se dão ao nível das consequências." COÊLHO, Sacha Calmon Navarro. Teoria Geral do Tributo, da Interpretação e da Exoneração Tributária (O Significado do art. 116, parágrafo único, do CTN). São Paulo: Dialética, 2003. p. 200.

${ }^{46}$ Conforme indica Heleno Tôrres: "Concernente ao regime do Direito Tributário Internacional, a isenção é predisposta para excluir da tributação (interna) os fatos formadores de renda caracterizados por elementos de estraneidade, quando produzidos fora do território do Estado tributante. Esta é a única diferença em relação às demais normas isentivas aplicáveis no interior do sistema: a presença de elementos de estraneidade no fato-evento descrito na hipótese de incidencia das normas de Direito Tributário Internacional.” TÔRRES, Heleno. Pluritributação Internacional sobre as rendas de empresas. $2^{a}$ ed. rev., atual e ampl. - São Paulo: Editora Revista dos Tribunais, 2001. p. 431.

${ }^{47}$ XAVIER, Alberto. Direito tributário internacional do Brasil. $6^{a}$ ed. atualizada - Rio de Janeiro: Forense, 2004 . p. 814.

\footnotetext{
${ }^{48}$ Pires aun presenta las modalidades condicionada e incondicionada, aunque en la secuencia ya presenta reservas a dicha clasificación: "A isenção incondicional verifica-se ainda que o Estado com poder de tributar não exerça esse poder, contrariamente à isenção condicionada que depende da tributação no Estado a que é reconhecido o poder de tributar. Nesta modalidade, diferentemente da primeira, elimina-se, portanto, apenas a dupla tributação efectiva. Já foi sustentado não estabelecer o método da isenção necessariamente qualquer condição no que respeita à tributação no outro Estado, ainda que se suponha que nele de verificará a tributação. Esta seria a diferença em relação à isenção derivada do método da repartição ou atribuição. No entanto, nada impede, como se viu, que se exija a verificação dessa tributação - o que sucede similarmente quando se estabelece a regra da sujeição a imposto (subject to tax) que, aliás, não implica sempre a tributação efectiva, por que se esta não operar em virtude de dedução, continuará a considerar-se verificada a regra -, nem esse facto impõe por si o desvirtuamento da figura. (...)” PIRES, Manuel. Da dupla tributação jurídica internacional sobre o rendimento. Lisboa, Centro de Estudos Fiscais - Ministério das Finanças, 1984. p. 340-343.
} 
prevista, considerándola para efectos de fijación de alícuota progresiva y eventuales sobre alícuotas. La doctrina española converge en este punto. ${ }^{49}$

Por fin, nos parece relevante mencionar una metodología de naturaleza no tributaria pero sí contable, que también visa la reducción del impacto de la doble imposición tributaria, es la concesión a la sociedad de la posibilidad de adopción del valor del tributo recolectado en el exterior como gasto incurrido por la sociedad en el desempeño de sus actividades. De esta forma, cuando utilizadas metodologías de apuración basadas en bases efectivas (no simplificadas o presumidas) tal gasto sería factor reductor del lucro líquido, parcela efectivamente tributada ${ }^{50}$.

\footnotetext{
${ }^{49}$ Así disponen: "O método da isenção comporta duas modalidades: ou o rendimento não é tido em consideração seja para que efeito for - e temos a isenção integral; ou o rendimento, apesar de não ser tributado, é tomado em consideração, conjuntamente com os de produção interna, para o efeito de determinar a alíquota progressiva aplicável à renda global e temos isenção com progressividade, isenção qualificada ou método de alíquota efetiva. Claro que este método só é relevante caso o imposto no Estado da residência tenha caráter progressivo e não proporcional." XAVIER, Alberto. Direito tributário internacional do Brasil. $6^{a}$ ed. atualizada - Rio de Janeiro: Forense, 2004. p. 815-816.;
}

\footnotetext{
"Na isenção dita integral ou pura (full exemption), o Estado abstém-se de submeter a qualquer imposição os elementos redituais de fonte estrangeira, excluindo-os da base de calculo dos impostos internos. Em termos de eficácia técnica, o método da isenção integral permite a priori evitar, de modo mais seguro, o fenômeno da bitributação internacional, na medida em que mantém os contribuintes que produzem renda no exterior submetidos a um único ordenamento impositivo (...). O outro método é o da isenção com progressividade (exemption avec progressivité), que, em breves termos, se trata da aplicação de um imposto progressivo condicionado pela isenção, por que a matéria tributável de fonte estrangeira ou situada no estrangeiro não entra na formação da base de calculo do imposto devido internamente, mas é levada em consideração para calcular o quantum debeatur de imposto, sob alíquota progressiva." TÔRRES, Heleno. Pluritributação Internacional sobre as rendas de empresas. $2^{\text {a }}$ ed. rev., atual e ampl. - São Paulo: Editora Revista dos Tribunais, 2001. p. 433-436;
}

\footnotetext{
"Según el método de exención, el Estado de residencia del inversor exime de tributación determinados tipos de renta de fuente extranjera. En otras palabras, este país concede al Estado donde la renta es generada - Estado de la fuente - el derecho exclusivo a someter a tributación dicho tipo de renta. El Estado de residencia puede considerar dicha renta a los efectos del cálculo del tipo de gravamen aplicable a la base imponible para así respetar la progresividad del sistema tributario (Método de exención con progresividad). Como regla general, estas exenciones están confinadas a los beneficios obtenidos por establecimientos permanentes, rentas obtenidas por expatriados y rentas inmobiliarias de bienes situados en el extranjero. La exención íntegra de tributar por la renta de fuente extranjera en el Estado de residencia, pone en la misma situación de igualdad tributaria al inversor extranjero en relación con los residentes en el Estado de la fuente. De esta manera, los beneficios fiscales concedidos por el Estado de la fuente no son ni reducidos ni eliminados por el Estado de residencia." ANTÓN, Fernando Serrano. Los principios básicos de la fiscalidad internacional y los convenios para evitar la doble imposición internacional: historia, tipos, fines, estructura y aplicación. In: Fiscalidad Internacional. 2a ed. rev. y ampl. Madrid: Centro de Estudios Financieros, 2005. p. 222.

${ }^{50}$ Algunos autores aun mencionan como medida unilateral, para evitar la doble tributación, la estipulación de crédito de impuesto o gasto deducible para el socio nacional que recibió dividendos de la empresa en el exterior. En estos casos, tal crédito sería del tributo pagado por la sociedad extranjera cuando de la apuración de sus ganancias.

Exceptuando expresamente las hipótesis de transparencia fiscal, que serán oportunamente analizadas, no entendemos el crédito de tributo societario como método destinado a la eliminación de la doble tributación, sobre todo teniendo en cuenta la falta de identidad entre la sociedad extranjera y la persona del socio. La simple identidad de la renta, por sí, no puede ser elemento suficiente para la caracterización de tal doble tributación. Así, la consideración de este crédito, inclusive en los moldes propuestos por la OCDE debe, según nuestro entendimiento, ser considerado como un simple beneficio fiscal.
} 


\section{Bibliografía referenciada}

Adonnino, P. (2001). Parecere del Ministero delle finanze e del Comitato Consultivo per l'aplicazione delle norme antielusive e rilevanza penale dell'elusione. Rivista di Diritto Tributario.

Airey, S. (2020). "Taxation Untapped: The Potential of the UN Sustainable Development Goals to Promote Progressive International Tax Reform". UCD Working Papers in Law, Criminology \& Socio-Legal Studies. Research Paper No. 6 /2020, 10.

Antón, F. S. (2005). Los principios básicos de la fiscalidad internacional y los convenios para evitar la doble imposición internacional: historia, tipos, fines, estructura y aplicación. Fiscalidad Internacional. Madrid: Centro de Estudios Financierso (CEF).

Asamblea General, Naciones Unidas. (9 de Octubre de 2013). Documento final del acto especial de seguimiento de la labor realizada para lograr los Objetivos de Desarrollo del Milenio, A/68/L.4. Obtenido de https://undocs.org/es/A/RES/68/6

Asamblea General, Naciones Unidas. (27 de Julio de 2015). La resolución 69/2013 de la Asamblea General Tercera Conferencia Internacional sobre la Financiación para el Desarrollo (Agenda de Acción de Addis Abeba). Obtenido de https://unctad.org/meetings/es/SessionalDocuments/ares69d313_es.pdf

Baleeiro, A. (1964). Uma introdução à Ciência das Finanças e à Política Fiscal. Rio de Janeiro: Forense.

Bianco, J. (2007). Transparência fiscal internacional. São Paulo: Dialéctica.

Bifano, E. (2009). Apuração de Preços de Transferência em Intangíveis, Contratos de Prestação de Serviços, Intragrupo e Cost Sharing Agreements. São Paulo: Dialética.

Buffon, M. (2009). Tributação e dignidade humana: entre os direitos e deveres fundamentais. Porto Alegre, Brasil: Livraria do Advogado Editora.

Bujanda, F. S. (1963). Hacienda y Derecho. Estudios e Derecho Financiero III. Madrid: Instituto de Estudios Fiscales (IEF).

Coêlho, S. C. (2003). Teoria Geral do Tributo, da Interpretação e da Exoneração Tributária . São Paulo: Dialética.

Coêlho, S. C. (2003). Teoria Geral do Tributo, da Interpretação e da Exoneração Tributária . São Paulo: Dialética.

Costerano, M. (2006). Cláusulas Gerais Antielusivas. Edições Almedina.

Doria, A. R. (1971). Elisão e evasão fiscal . São Paulo: Lael.

Ferreiro Lapatza, J. J. (2006). Curso de Derecho financiero español. Madrid: Marcial Pons. Hearson, M. (2019). Fair tax for development. Reino Unido: United Nations-UK. 
Hilling , A., \& Ostas, D. (14 de Mayo de 2018). Corporate Income Taxation, CSR and the UN's 2030 Agenda for Sustainable Development. Wolters Kluwer.

Kaldor , N. (Enero de 1963). Will Underdeveloped Countries Learn to Tax? Foreign Affairs, 41(2), 410-419. doi:10.2307/20029626

Long, C., \& Miller, M. (Abril de 2017). Taxation and the Sustainable Development Goals Do good things come to those who tax more? Obtenido de https://www.odi.org/sites/odi.org.uk/files/resource-documents/11536.pdf

OECD. (2010). Transfer Pricing Guidelines for Multinational Enterprises and Tax Administrations. OECD .

Organización de las Naciones Unidas (ONU). (19 de febrero 2019). Reportaje Naciones

Unidas Brasil: La ONU llama a los países en desarrollo a luchar contra la evasión fiscal por objetivos globales.

Organización de las Naciones Unidas (ONU). (2002). Proyecto del Milenio .

Pires, M. (1984). Da dupla tributação jurídica internacional sobre o rendimento. Lisboa: Centro de Estudos Fiscais - Ministério das Finanças.

Pires, M. (1984). Da dupla tributação jurídica internacional sobre o rendimento. Lisboa: Centro de Estudos Fiscais - Ministério das Finanças.

Thomas Worster, W. (24 de Junio de 2010). The Constitutionality of the Taxation Consequences for Renouncing U.S. Citizenship. Florida Tax Review, 9(11), 100.

Tôrres, H. (2001). Pluritributação Internacional sobre as rendas de empresas. São Paulo: Editora Revista dos Tribunais.

Troianelli, G. L. (2001). Comentários aos novos dispositivos do CTN: A LC 104. São Paulo: Dialética.

Viladomat, M. (2004). El régimen Fiscal de los Precios de Transferencia. En T. Ezquerro, Manual de FIscalidad Internacional (Segunda ed., pág. 445). Madrid: Instituto de Estudios Fiscales (IEF).

Xavier, A. (2004). Direito tributário internacional do Brasil. Rio de Janeiro : Editora Forense

Yamashita, D. (2005). Elisão e evasão de tributos: planejamento tributário: limites à luz do abuso do direito e da fraude à lei. Lex Editora . 